Diterima : 17-4-2020 Revisi : 19-6-2020Ｄipublikasi : 25-6-2020

\title{
K-POP NON-KOREA BUKAN APROPRIASI BUDAYA : ANALISIS WACANA KRITIS MODEL TEUN VAN DIJK
}

\author{
Dwi Windah Wulansari
}

\author{
Universitas Airlangga \\ Jl. Dharmawangsa Dalam, Airlangga, Gubeng, Kota Surabaya, Indonesia \\ Pos-el:Dwiwindah_wulansari@yahoo.co.id
}

\begin{abstract}
This research supports the structure of critical discourse when viewed from the perspective of Teun Van Dijk. The data source used was a video uploaded by the Indonesian representative entitled K-POP Non Korea EXP Edition. The method used is descriptive qualitative. The results of the analysis show that non-Koreans can be part of K-pop. Various pros and cons experienced by this EXP EDITION boy band, did not ignite their enthusiasm for a career in South Korea. The phenomenon in this EXP EDITION. Positive and negative opinion. Most of the supporters of this boy band because they see their efforts are not instantaneous as previously reported. Some consider that they are giving up Korean culture or what is cooler is called cultural appropriation. Associated with the practice of power and discourse accents. The practice of power in this non-Korean K-pop phenomenon. Reporting from the Columbia University official website, Bora Kim formed the EXP EDITION group and mapped it out with the aim of "discussing what Kpop and Kpop fandom are".
\end{abstract}

Keywords : boyband, EXP Edition, K-pop, critical discourse. Van dijk.

\begin{abstract}
Abstrak
Penelitian ini bertujuan untuk menegtahui struktur wacana kritis jika dilihat dari prespektof Teun Van Dijk. Sumber data yang digunakan adalah video yang di upload oleh Vice Indonesia yang berjudul K-POP Non Korea EXP Edition. Metode yang digunakan adalah deskriptif kualitatif. Hasil analisis menujukkan bahwa orang non-Korea bisa menjadi bagian dari Kpop. Berbagai pro dan kontra yang dialami oleh boyband EXP EDITION ini, tidak menyulutkan semangat mereka untuk berkarir di Korea Selatan. $D i$ dalam video ini memuat berbagi pendapat mengenai fenomena EXP EDITION ini. Pendapat yang positif maupun negatif. Sebagian banyak
\end{abstract}


yang mendukung boyband ini karena melihat usaha mereka yang tidak instan seperti yang dikabarkan sebelumnya. Sebagian lagi menganggap bahwa mereka mencuri budaya Korea atau yang lebih keren disebut apropriasi budaya. Berhubungan dengan praktik kekuasaan dan aksen wacama. Praktik kekuasaan dalam fenomena K-pop non-Korea ini. Dilansir dari situs web resmi Columbia University, Bora Kim membentuk grup EXP EDITION dan mendokumentasikannya dengan tujuan "mengeksplorasi mengenai apa itu Kpop dan fandom Kpop".

Kata-kata Kunci : boyband, EXP Edition, K-pop, wacana kritis. Van dijk.

\section{PENDAHULUAN}

Demam K-pop telah melanda hampir seluruh belahan dunia, dan mungkin oleh sebab itulah, orang-orang non-Korea tertarik untuk membuat boyband. Menjadi seorang bintang K-pop tidaklah mudah, perlu kerja keras dan pertimbangan yang matang, bayak yang harus dijalani seperti latihan yang cukup padat setiap harinya sekitar 10 jam per hari dan diet yang ketat agar membentuk badan yang ideal oleh karena itu, tidak mudah bisa merambah indutri k-pop. Seluruh penjuru dunia bahkan mengakui bahwa kesuksesan Kpop sangat berpengaruh terhadap pasar global. Dari sinilah alasan penulis mengunakan video dari Youtube yang dirilis oleh VICE Indonesia sebagai objek penelitian. Vidio ini di publish 28 November 2018 yang berjudul The World's First Non-Korean K-POP Group.

Di dalam video yang berdurasi kurang lebih 27 menit ini, menceritakan tentang boyband nonKorea yang menyebut diri mereka K-pop. Boyband itu adalah EXP EDITION, beranggotakan 4 orang pemuda yang beraneka ragam asal, yaitu Koki Tomlinson merupakan pria berdarah Jepang dan Jerman. Frankie Da Ponte berdarah Portugis, Hunter Kohl adalah penduduk asli New York, Amerika Serikat dan Šime Košta berasal dari Kroasia. Mereka hijrah dari New York ke Seoul, Korea Selatan untuk membangun karier mereka sebagai grup K-pop. Hal itu yang menjadi alasan mereka mengusung tagline 'Born in NY, made in Seoul'. Selain akan melakukan re-debut di Korea Selatan, keempatnya juga akan mendalami budaya Korea, belajar bernyanyi, dance, dan belajar bahasa Korea untuk menjadi boyband K-pop yang sesungguhnya.

EXP EDITION didirikan oleh tiga perempuan cantik yaitu Bora Kim, Karin Kuroda, dan Samantha Y. Shao. L yang memiliki gagasan yang sama untuk membentuk grup K-pop. Namun didalam grup tersebut berisikan bukan orang korea. Bora Kim memiliki tujuan untuk "mengeksplorasi mengenai apa itu K-pop dan fandom K-pop". Proyek ini diberi judul I'm Making a Boy Band. Proyek ini bahkan berhasil mengumpulkan $\$ 30.000$ di 
laman Kickstarter, yaitu platform pendanaan untuk proyek-proyek kreatif. Pada 2015 lalu Bora Kim menyatakan bahwa ia ingin mengetahui apa yang terjadi jika dia membentuk laki-laki asal Amerika Serikat menjadi K-pop performers. Dengan mengajari mereka bernyanyi dalam bahasa Korea, dan bersikap seperti laki-laki Korea. Namun, EXP Edition membantah bahwa penelitian Kim Bora dan teman-temannya sudah selesai. Dan kini EXP EDITION bukanlah sebuah objek penelitian riset melainkan boyband K-pop yang siap untuk debut di Korea Selatan.

Pertama kali muncul, EXP EDITION langsung dihujani kritik pedas dari pada penggila K-pop. EXP EDITION dianggap sudah mencuri salah satu budaya Korea. Namun, menurut sudut pandang anggota EXP EDITION, kritik pedas macam ini biasanya dilayangkan kepada siapapun yang menjajal genre musik yang popularitasnya tengah menanjak di kancah global. EXP EDITION dirasa melakukan apropriasi budaya. Maksudnya adalah EXP EDITION menggunakan budaya Korea sebagai aksesoris untuk kepentingan sendiri yang mana EXP EDITION bukanlah pengikut atau bagian dari budaya tersebut. hal ini menajadi perdebatan oleh fans Kpop sendiri karena merasa EXP EDITION merupakan artis instan karena tidak mengalami perjalanan panjang seperti para bintang Korea lainnya. \begin{tabular}{lrr}
\multicolumn{2}{c}{ Dalam wawacaranya } \\
bersama Vice, EXP & EDITION \\
menyebutkan bahwa & mereka \\
percaya, menjadi musisi & K-pop \\
tidak sepenuhnya dimonopoli & \\
penduduk Negeri Ginseng. Alasan \\
memilih topik ini adalah karena \\
fenomena $\quad$ K-pop & sedang
\end{tabular} digandrungi oleh remaja saat ini. Tidak banyak yang tahu jika proses menjadi artis K-pop tidak mudah, oleh karena itu penulis ingin meneliti fenomena bintang K-pop yaitu EXP EDITION dalam usaha mereka menjadi artis K-pop melalui pendekatan Van Dijk. Dalam analisis CDA yang dikemukakan oleh Van Dijk berisi tentang wacana, kognisi sosial, dan masyarakat. Tujuan dari penelitian ini adalah untuk mengeksplorasi fenomena bintang K-pop non-Korea yang ada dalam video Vice Indonesia seperti interaksi percakapan, latar, dan dimensi 'semiotik' atau multimedia apa pun dari penandaan. Kemudian, penulis ingin menemukan bagaimana kognisi sosial berhubungan dengan ideologi dan tujuan serta evaluasi dan emosi, beberapa lainnya seperti 'mental' dan 'memori' struktur, representasi atau proses yang terlibat dalam wacana dan interaksi. Terakhir, penulis ingin mengetahui analisis sosial dari video ini dengan mengetahui bagaimana masyarakat berhubungan dengan interaksi lokal dan hubungan kelompok (Wodak, 2002). Peneliti ingin mencari tahu apa makna yang ingin di sampaikan oleh VICE terhadap boyband K-pop EXP EDITION dan bagaimana 
kognisi sosial dan analisis sosial terhadap boyband K-pop EXP EDITION

\section{METODE PENELITIAN}

Metode penelitain yang digunakan adalah deskriptif kualitatif, dengan penjabaran sebagai berikut :

\begin{tabular}{|c|c|c|c|c|}
\hline $\mathrm{NO}$ & $\begin{array}{l}\text { Rumusan } \\
\text { Masalah }\end{array}$ & Sumber Data & Pengumpulan Data & Analisis Data \\
\hline 1. & $\begin{array}{l}\text { Makna yang } \\
\text { ingin di } \\
\text { sampaikan oleh } \\
\text { VICE terhadap } \\
\text { Boyband K-pop } \\
\text { EXP EDITION }\end{array}$ & Video VICE & $\begin{array}{l}\text { Bertemu dengan } \\
\text { EXP EdDITION }\end{array}$ & $\begin{array}{l}\text { 1. Struktur } \\
\text { makro } \\
\text { 2. Suprastruktur } \\
\text { 3. Struktur } \\
\quad \text { mikro }\end{array}$ \\
\hline 2. & $\begin{array}{l}\text { Kognisi sosial } \\
\text { terhadap } \\
\text { boyband K-pop } \\
\text { EXP EDITION }\end{array}$ & Video VICE & $\begin{array}{l}\text { 1.Wawancara dengan } \\
\text { vlogger dan } \\
\text { youtubber } \\
\text { 2.Wawancara dengan } \\
\text { pihak EXP } \\
\text { EDITION } \\
\text { 3.Wawancara dengan } \\
\text { Bora Kim dan } \\
\text { teman-temannya. } \\
\text { 4.Wawancara dengan } \\
\text { fans EXP EDITION }\end{array}$ & $\begin{array}{l}\text { Pengetahuan } \\
\text { mereka tentang } \\
\text { K-pop dan } \\
\text { apropriasi } \\
\text { budaya. }\end{array}$ \\
\hline 3. & $\begin{array}{lr}\text { Analisis sosial } \\
\text { yang terdapat } \\
\text { dalam } \\
\text { kelompok K- } \\
\text { pop EXP } \\
\text { EDITION? }\end{array}$ & Video VICE & $\begin{array}{lr}\text { Hubungan } & \text { antara } \\
\text { fenomena } & \text { K-pop } \\
\text { dengan masyarakat. }\end{array}$ & 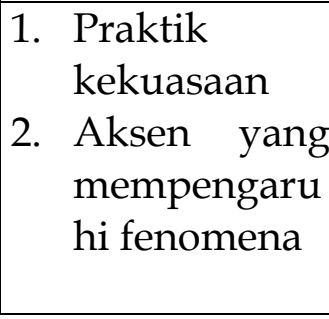 \\
\hline
\end{tabular}

\section{HASIL PENELITIAN DAN PEMBAHASAN}

Analisis data yang digunakan adalah model analisis Teun A Van Dijk. Model analisisnya mengamati tiga hal yaitu wacana, kognisi sosial, dan analisis sosial. Van Dijk membaginya menjadi tiga tingkatan yaitu struktur makro, superstruktur, dan struktur mikro (Eriyanto, $2016:$ 227).

1. Makna Yang Ingin Di Sampaikan Oleh Vice Terhadap Boyband K-Pop EXP EDITION

Pada fenomena kelompok Kpop EXP EDITION yang fenomenal, 
dimensi yang diteliti adalah makna yang ingin disampaikan oleh Vice menganai fenomena tersebut. Berdasarkan teori dari Van Dijk, terdiri dari tiga struktur yang dianalisis. Masing-masing struktur menjadi bagian yang saling mendukung. Yaitu struktur makro, superstruktur, dan struktur mikro. Didalam struktur makro hal yang diamati dalam struktur ini adalah tematik atau tema. Tema dari fenomena ini adalah orang nonKorea bisa menjadi bagian dari Kpop. Berbagai pro dan kontra yang dialami oleh boyband EXP EDITION ini, tidak menyulutkan semangat mereka untuk berkarir di Korea Selatan. Meskipun banyak yang menghujat, menurut EXP EDITION hal itu lumrah terjadi kepada siapapun yang menjajal genre musik yang popularitasnya tengah menanjak di kancah global.

$$
\text { Kedua, pengamatan }
$$
superstruktur yang berfokus pada skema penulisan. Hal yang diamati seputar bagaimana bagian dan urutan berita diskemakan dalam teks berita menjadi sebuah berita utuh. Dilihat secara skematik, fenomena kelompok K-pop EXP EDITION ini memiliki skema tidak berurutan. Gagasan utama berada di akhir. Dimana mereka menegaskan bahwa mereka bisa menjadi boyband K-pop karena mereka belajar bahasa Korea dan tinggal di Korea Selatan. Pada awal video ini, diperkenalkan siapa EXP EDITION itu, lalu menampilkan hujatan yang ditujukan oleh para fans K-pop yang tidak menerima keberadaan EXP EDITION di industrI K-pop, dilanjutkan dengan menelisik keseharian EXP EDITION dan siapa yang membangun kelompok K-pop ini, dan yang terakhir wawancara dengan beberapa vloger mengenai pantas atau tidaknya EXP EDITION berada di Industri K-pop.

Terakhir adalah struktur mikro, hal yang diamati dalam struktur mikro ada empat fokus pengamatan. Yaitu pengamatan dari sisi semantik, sintaksis, stilistik, dan retoris. Akan tetapi yang dibahas dalam penelitian ini hanya semantik dan retoris saja. Pertama, pengamatan semantik yang mengulik latar, detil, maksud dari tulisan. Pengamatan ini akan menguraikan makna yang ingin ditekankan penulis dalam berita dengan strategi penulisan latar, detail, dan maksud tulisan. Latar keadaan yang paling dominan di tunjukkan dalam video VICE tersebut. keadaan dimana pihak VICE meminta pendapat mengenai EXP EDITION yang berkarir di Korea Selatan kebanyakan membuat para vlogger marah dan meremehkan EXP EDITION. Karena menganggap EXP EDITION tidak layak disebut K-pop, bukan hanya karena wajah bule mereka namun dalam hal pelafalan bahasa Korea, EXP EDITION dirasa masih tidak bisa melafalkannya dengan baik.

Dibuktikan dengan pilihan kata yang digunakan para vlogger dan youtuber tersebut yaitu: engak asik, tidak tertarik untuk melihatnya, kemampuannya segitu 
aja, terlihat palsu karena memaksakan diri menyanyikan lagu K-pop, mereka akan tetap berada dibawah lampu sorot yang menyilaukan. Yang kedua, retoris meneliti tentang gaya penyampaiannya. Apakah melalui grafis, ekspresi, atau metafora. Gaya penyampain pihak VICE sangat ekspresi, dan mereka tidak merujuk pada satu informan saja, namun banyak informan yang di wawancarai oleh karena itu banyak ekspresi yang ditunjukkan responden untuk menanggapi pertanyaan dari VICE mengenai Kpop non-Korea ini sangat beragam.

\section{Kognisi Sosial Terhadap Boyband K-Pop EXP EDITION}

Bagian kedua dari teori Van Dijk berkaitan dengan kognisi sosial, ideologi dan tujuan serta evaluasi dan emosi, beberapa lainnya seperti 'mental' dan 'memori' struktur, representasi atau proses yang terlibat dalam wacana dan interaksi (Wodak , 2012).

Di dalam video ini, reporter VICE menyampaikan fenomena ini dengan bahasa yang mudah dipahami oleh penonton. Di dalam video ini memuat berbagi pendapat mengenai fenomena EXP EDITION ini. Pendapat yang positif maupun negatif. Sebagian banyak yang mendukung boyband ini karena melihat usaha mereka yang tidak instan seperti yang dikabarkan sebelumnya. Mereka melewati halhal tersulit seperti belajar dance dan belajar bahasa korea. Itu tidak mudah, karena mereka harus bernyanyi menggunakan bahasa korea yang menurut mereka bahasa Korea itu asing. Di awal video, menceritakan tentang perkenalan anggota EXP Edition, keseharian mereka, wawancara dengan pengajar dance yang paling pupuler di Korea Selatan dan bertanya apa pendapat Lia Kim tentang fenomena ini. Menurut Lia Kim, idol K-pop sebenarnya bisa dibentuk, bukan hal yang mustahil jika orang non-Korea ingin menjadi bintang K-pop.

Pendapat kedua dikemukakan oleh Danny dan David adalah youtuber Korea pupuler, mereka mengomentari tentang video clip dari EXP EDITION, menurut dua youtuber ini, EXP EDITION dianggap buruk, sangat lucu menurut dua youtuber ini jika EXP EDITION dianggap sebagai bintang K-pop karena lagu mereka terdengar sangat pop, mereka terkesan seperti meniru dengan memakai make-up dan gaya K-pop, dan terdengar aneh saat mereka mengucapkan bahasa Korea di lagunya. Youtuber ini menganggap bahwa EXP EDITION adalah proyek pendek yang tidak akan bisa bertahan lama dan mencapai debutnya di ranah K-pop. Didalam video ini dilanjutkan dengan penampilan EXP EDITIONN di Kuil Budha di Korea, dan wawancara dengan beberapa fans EXP EDITION yang mendukung EXP EDITION karena mereka berkarya dengan baik. EXP EDITION menceritakan bahwa penghujat mereka bukan berasal dari Korea 
namun di luar Negara Gingseng tersebut. Dan pihak VICE juga menampilkan youtuber yang memang menghujat EXP EDITION ini, EXP EDITION dianggap melakukan apropriasi budaya. Tetapi yang paling penting di Korea Selatan tidak ada reaksi kebencian semacam itu. Korea memiliki pengertian yang berbeda mengenai aproprisasi budaya K-pop. Para youtubber yang menghujat EXP EDITION seakan-akan mereka adalah duta besar K-pop yang mempunyai wewenang siapa saja yang termasuk dalam artis K-pop.

Masyarakat harus lebih pintar ketika memilih kata, apakah yang dilakukan EXP EDITION adalah apropriasi budaya bukan apresiasi terhadap budaya mereka. Jika mereka menyebut itu apropriasi, EXP EDITION akan membawa budaya Korea ke tempat asalanya dan memakainya sebagai identitas diri mereka di tempat asalnya New York. Namun, yang terjadi tidaklah seperti itu, EXP EDITION tinggal menetap di Korea Selatan demi mengebangkan karir di Negara Gingseng tersebut. Mereka berlatih keras untuk belajar bahasa Korea dan meninggalkan keluarga demi bisa berkarir di Korea Selatan. Seharusnya mereka mendapatkan apresiasi dari banyak orang. Secara tidak langsung EXP EDITION ikut melestarikan apa yang disebut dengan budaya K-pop.

\section{Analisis sosial yang terdapat dalam kelompok K-pop EXP Edition}

Analisis sosial berkaitan dengan hal-hal yang mempengaruhi pemakaian bahasa dan terbentuknya sebuah wacana. Seperti latar, situasi, peristiwa, dan kondisi sosial yang terjadi saat itu. Pada konteks sosial tertentu, sebuah wacana dapat diteliti, dianalisis, dan dimengerti (Eriyanto, 2017).

Disini penulis menganalisis praktik kekuasaan dalam fenomena K-pop non-Korea ini. Praktek kekuasaan ini dipengaruhi oleh latar belakang berdirinya EXP EDITION. Dilansir dari situs web resmi Columbia University, Bora Kim membentuk grup EXP EDITION dan mendokumentasikannya dengan tujuan "mengeksplorasi mengenai apa itu Kpop dan fandom Kpop". Proyeknya mendapat pendanaan dari Kickstarer. Kerumitan akan proyek ini jadi jauh lebih kompleks karena dirinya berada di New York, di mana begitu banyak talents yang mendaftar meskipun Kim hanya memasang iklan online.

Kim mempresentasikan proyek MFA-nya pada tahun 2015 silam, dengan catatan bahwa grup boyband-nya masih "sedang dibentuk". Sejak saat itu, Kim dan grupnya harus pindah ke Korea Selatan, di mana Kim membentuk IMMABB Entertainment sebagai sebuah agensi. Sebagai grup K-pop pertama yang dibentuk di New York, EXP EDITION mencakup berbagai budaya dan genre musik. Walaupun tidak ada satupun anggota yang merupakan orang Korea, EXP EDITION mengatakan 
bahwa musik mereka adalah K-pop karena mereka juga mampu menari, lagu mereka berbahasa Korea dan menyukai budaya fandom Korea.

Kedua, akses yang mempengaruhi fenomena ini adalah sikap para youtuber dan vlogger yang kebanyakan menghujat EXP EDITION dan menganggap mereka sebagai apropriasi budaya karena menurut mereka masyarkat nonkorea tidak bisa menjadi K-pop. EXP EDITION dirasa terlalu instan jika mereka menyebut diri mereka sebagai K-pop. Mereka tidak terlalu mempunyai daya tarik untuk dibilang sebagai K-pop. Bahasa Korea mereka masih amburadul. Mereka hanya mengadopsi gaya make-up dan dance Korea saja. Sedangkan menurut fans dari EXP EDITION, EXP EDITION patut mendapat pujian dan apresiasi karena mereka sudah bekerja keras dalam bernyanyi menggunkan bahasa Korea. Belajar bahasa Korea tidaklah mudah. Mereka juga mengalami hal yang sulit ketika harus belajar bahasa Korea dan dance. Setidaknya mereka berusaha untuk menjadi K-pop yang berkualitas.

Pandangan dari EXP EDITION, hujatan semacam itu lumrah terjadi ketika seseorangan akan mencapai puncak kejayaan mereka. Akan tetapi hujatan tersebut tak mematahkan semangat mereka untuk berkarya. Mereka sudah meninggalkan segalanya demi pergi ke Korea Selatan untuk menjadi bintang K-pop di Korea Selatan. Mereka meninggalkan orang tua dan sanak saudara dan itu merupakan keputusan dan pertimbangan yang sangat besar. Mereka ingin sukses di ranah K-pop karena K-pop yang paling digandrungi saat ini. Menurut EXP EDITION, mereka bukan artis instan yang tampa belajar bisa langsung terkenal, karena sebelumnya di New York, mereka sudah mengikuti audisi yang diselenggarakan oleh Bora Kim dan teman-temannya. Setelah itu EXP EDITION diusung ke Korea dan memulai karirnya di Korea.

\section{SIMPULAN}

Setelah menganalisa dan menjelaskan data pada bagian sebelumnya, maka pada bagian penutup peneliti mengambil kesimpulan dari rumusan masalah sebagai berikut:

1. Fenomena bintang K-pop non-Korea dilihat dari dimensi makna Teun Van Dijk, antara lain:

a. Stuktur makro berisi temaema dari fenomena ini adalah orang nonKorea bisa menjadi bagian dari K-pop. Berbagai pro dan kontra yang dialami oleh boyband EXP EDITION ini, tidak menyulutkan semangat mereka untuk berkarir di Korea Selatan.

b. Superstructure meilihat secara skematik, fenomena kelompok Kpop EXP EDITION ini memiliki skema tidak 
berurutan. EXP EDITION menegaskan bahwa mereka bisa menjadi boyband K-pop karena mereka belajar bahasa Korea dan tinggal di Korea Selatan.

c. Struktur mikro membahas tentang pengamatan semantik dan reoris. Pengamatan ini akan menguraikan makna yang ingin ditekankan penulis dalam berita dengan strategi penulisan latar yang dibuktikan dengan pilihan kata dalam video Vice. Latar keadaan yang paling dominan di tunjukkan dalam video VICE tersebut. keadaan dimana pihak VICE meminta pendapat mengenai EXP EDITION yang berkarir di Korea Selatan. Dibuktikan dengan pilihan kata yang digunakan para vlogger dan youtuber tersebut yaitu: engak asik, tidak tertarik untuk melihatnya, kemampuannya segitu aja, terlihat palsu karena memaksakan diri menyanyikan lagu K-pop, mereka akan tetap berada dibawah lampu sorot yang menyilaukan. Yang kedua, retoris meneliti tentang gaya penyampaiannya. Gaya penyampain pihak VICE sangat ekspresi, dan mereka tidak merujuk pada satu informan saja, namun banyak informan yang di wawancarai oleh karena itu banyak ekspresi yang ditunjukkan responden untuk menanggapi pertanyaan dari VICE mengenai K-pop nonkorea ini sangat beragam.

2. Mengenai kognisi social, didalam video ini, reporter VICE menyampaikan fenomena ini dengan bahasa yang mudah dipahami oleh penonton. Di dalam video ini memuat berbagi pendapat mengenai fenomena EXP EDITION ini. Pendapat yang positif maupun negatif. Sebagian banyak yang mendukung boyband ini karena melihat usaha mereka yang tidak instan seperti yang dikabarkan sebelumnya. Sebagian lagi menganggap bahwa mereka mencuri budaya Korea atau yang lebih keren disebut apropriasi budaya.

3. Analisis social memaparkan tentang praktik kekuasaan dan aksen wacama. Praktik kekuasaan dalam fenomena K-pop non-Korea ini. Praktek kekuasaan ini dipengaruhi oleh latar belakang berdirinya EXP EDITION. Dilansir dari situs web resmi Columbia University, Bora Kim membentuk grup EXP EDITION dan 
mendokumentasikannya

dengan

tujuan

"mengeksplorasi mengenai apa itu Kpop dan fandom Kpop". Dan yang kedua, akses yang wacana yang mempengaruhi fenomena ini adalah sikap para youtuber dan vlogger yang kebanyakan menghujat EXP EDITION dan menganggap mereka sebagai apropriasi budaya karena menurut mereka masyarkat non-korea tidak bisa menjadi K-pop. Sedaangkan para fans dan EXP EDITION sendiri tidak merasa bahwa itu apsopriasi budaya malah disebut sebagai apresiasi budaya.

\section{DAFTAR PUSTAKA}

Eriyanto. (2016). Analisis Wacana Pengantar Analisis Teks Media. Yogyakarta: LKiS . 2017. Analisis Framing.

Yogyakarta: LKiS.

Febriyanti, Riski. (2017). 11 Fakta Mencengangkan EXP EDITION, Grup K-Pop yang Beranggotakan Cowok-Cowok Asal Amerika. https://www.idntimes.co $\mathrm{m} /$ hype/entertainment/riz ki-febriyanti/11-faktamencengangkan-expedition-grup-k-pop-yangberanggotakan-cowokcowok-asal-amerikac1c2/full. Diakses 13 Desember 2019. https://www.youtube.com/watch? $\mathrm{v}=\mathrm{I} 4 \mathrm{gO}$ HYYGzTA. Diakses 10 Desember 2019. Kumparan, (2017). “EXP Edition, Empat Bule Anggota Boyband Bernuansa K-pop". https:// kumparan.com/@k umparanhits/exp-editionempat-bule-anggotaboyband-bernuansa-k-pop. Diakses 13 Desember 2019.

Masayu, Rahma Fitriani. (2018). “Gagal Ngetop, Idol Ini Ungkap Kejamnya Industri K-Pop". https://www.styl.id/celeb/1 138/gagal-ngetop-idol-iniungkap-kejamnya-industri-kpop. Diakses 13 Desember 2019.

Surtana, Ra'idah Azzyati. (2017). "EXP Edition: Boyband Kpop asal New York".

https://meramuda.com/new s-entertainment/exp-editionboyband-kpop-asal-newyork/. Diakses 13 Desember 2019.

Qurnain, Dzul. (2016). Analisis Wacana Berita Islamiphobia Amerika Setelah Terpilihnya Donald Trump Sebagai Presiden Amerika (Berita Hidayatullah Tanggal 19 November 2016 ). Online.Https:// www.academ ia.edu/30228980/Contoh_An alisis_Wacana_Teun_Van_Dij

k. Diakses 5 Desember 2019.

Wodak, Ruth. (2012). Methods of Critical Discourse Analysis. London, GBR: Sage Publications, Incorporated. 